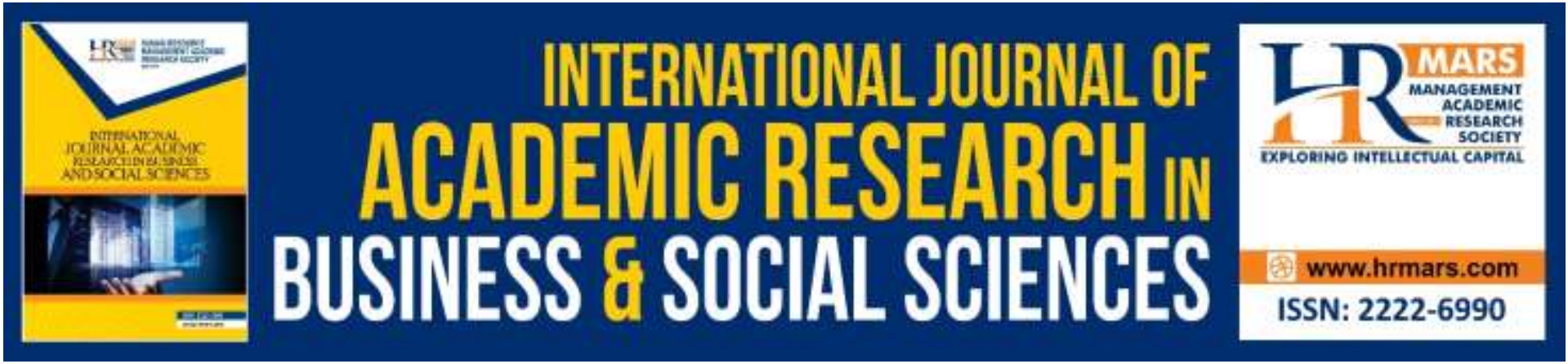

\title{
Revisiting Social Media Crisis Communication Model for Building Resilience via Artificial Neural Network Analysis
}

Umar Ali Bukar, Marzanah A. Jabar, Fatimah Sidi, Rozi Nor Haizan binti Nor, Salfarina Abdullah, Akmar Hayati Ahmad Ghazali

To Link this Article: http://dx.doi.org/10.6007/IJARBSS/v11-i17/11389～DOI:10.6007/IJARBSS/v11-i17/11389

Received: 11 August 2021, Revised: 07 September 2021, Accepted: 25 September 2021

Published Online: 09 October 2021

In-Text Citation: (Bukar et al., 2021)

To Cite this Article: Bukar, U. A., Jabar, M. A., Sidi, F., Nor, R. N. H. binti, Abdullah, S., \& Ghazali, A. H. A. (2021). Revisiting Social Media Crisis Communication Model for Building Resilience via Artificial Neural Network Analysis. International Journal of Academic Research in Business and Social Sciences, 11(17), 35-46.

Copyright: (C) 2021 The Author(s)

Published by Human Resource Management Academic Research Society (www.hrmars.com)

This article is published under the Creative Commons Attribution (CC BY 4.0) license. Anyone may reproduce, distribute, translate and create derivative works of this article (for both commercial and non-commercial purposes), subject to full attribution to the original publication and authors. The full terms of this license may be seen

at: http://creativecommons.org/licences/by/4.0/legalcode

Special Issue Title: Empowering Community and Beyond, iRandau, 2021, Pg. 35 - 46

Full Terms \& Conditions of access and use can be found at http://hrmars.com/index.php/pages/detail/publication-ethics 


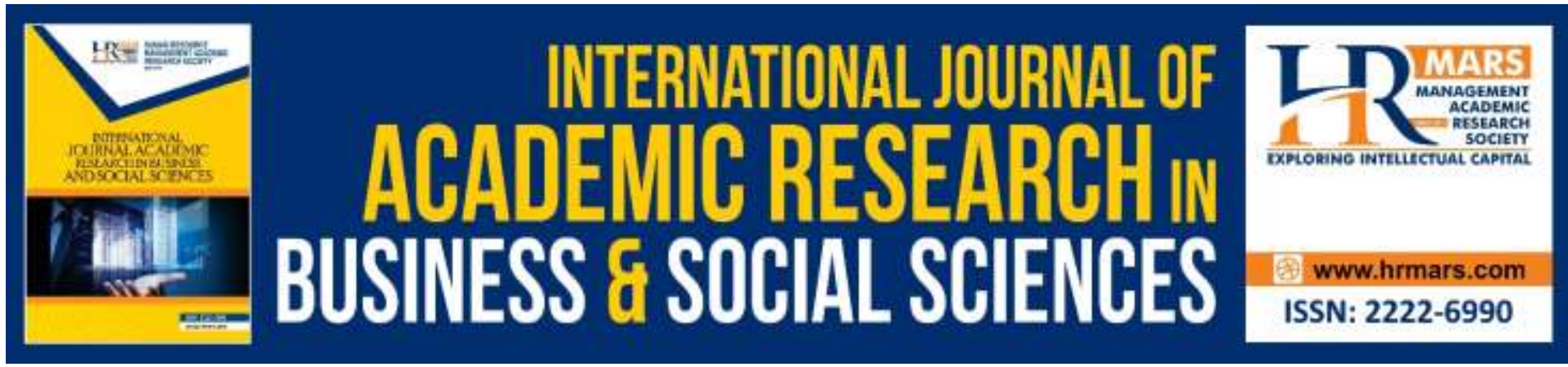

\title{
Revisiting Social Media Crisis Communication Model for Building Resilience via Artificial Neural Network Analysis
}

\author{
Umar Ali Bukar ${ }^{1}$, Marzanah A. Jabar, 1,2 Fatimah Sidi ${ }^{3}$, Rozi Nor \\ Haizan binti Nor ${ }^{1}$, Salfarina Abdullah ${ }^{1}$, Akmar Hayati \\ Ahmad Ghazali² \\ ${ }^{1}$ Department of Software Engineering and Information System, Faculty of Computer \\ Science and Information Technology, Universiti Putra Malaysia (UPM), Serdang 43400, 9, \\ Malaysia, ${ }^{2}$ Social Science Studies Institute, Universiti Putra Malaysia, Putra InfoPort, 43400 \\ UP, Serdang, Selangor Darul Ehsan, Malaysia, ${ }^{3}$ Department of Computer Science, Faculty of \\ Computer Science and Information Technology, Universiti Putra Malaysia (UPM), Serdang \\ 43400, Malaysia \\ Email: marzanah@upm.edu.my
}

\begin{abstract}
The devastating effects of crises and how social media usage assists or informs stakeholders are attracting attention recently. This study explored the literature on social media crisis communication and resilience and evaluated the predictors of public resilience and the impact of social media activities on public resilience. Using the artificial neural network (ANN) approach, this study sought to determine the effect of the crisis, crisis response, and social media interaction on public resilience. The ANN evaluates the mean value of the normalized performance from ten neural networks generated through cross-validation. The results indicate crisis response and social media interaction as the most significant predictors of resilience. Also, the findings show that it is desirable to continue studying the public's roles, motives, and actions on social media. The study offered theoretical justification to advance effective social media crisis management and communication.
\end{abstract}

Keywords: Social Media, Crisis Communication, Resilience, Social Interaction, ANN

\section{Introduction}

Over the last few years, research that looks at crisis communication dynamics has dramatically increased its investigation concerning social media usage in that respect (Coombs, 2017; Reuter \& Kaufhold, 2018; Reuter et al., 2018; Cheng, 2018; Comrie, 2019). During times of crisis, social media offer accessible, engaging, and versatile platforms through which organizations and the public engage each other, potentially enhancing crisis communication effectiveness (Reuter et al., 2018; Cheng, 2018) or increasing the crisis (Noguti, 2016). Social media has changed traditional crisis communication because of public participation in crisis discussions. This suggests that crisis-related information provided by 
crisis management (organizations) and the public on social media should be acknowledged, shared, and responded to (Coombs \& Holladay, 2012). Recent movements like as Christchurch shootings (Rahman, 2020), Black Lives Matter (AO \& Mak, 2021), Lekki massacre (Mmonu et al., 2021), and Covid19 (Schleicher, 2020) indicate that social media posts can rapidly spread and receive significant attention from all stakeholders. Crisis management is responsible for managing the crisis, and the public is affected by the crisis (AO \& Mak, 2021). Hence, with the explosion of social media and digital connectivity, social media users have the power to control the online narrative. The effects of this have impacted crisis management and communications (Morgan \& Wilk, 2021).

The advancement of technology and social media enables crisis information propagation by social media users and triggered by specific events, sustained discussion, and debates across multiple platforms that fuel widespread public interest, commonly known as social interaction (Cheng, 2018). However, several studies viewed social media as an avenue that unfolds another crisis (secondary crisis) (Austin et al., 2012; Liu et al., 2011; Zheng et al., 2018). These studies see the general public response as affecting crisis management or organizational reputation, which demonstrates public activism in publishing harsh comments on social media, targeting to tarnish the organization's image responsible for the crisis (Zheng et al., 2018). Hence, the effect of the crisis and how social media is helping the affected citizens or used as an information source is the research domain this study explored (Groen et al., 2017; Reuter \& Kaufhold, 2018).

In the event of a crisis, effective crisis communication is vital to manage the situation effectively successfully. It is critical to understand the general public's reaction to an emergency so that crisis management can plan and implement a crisis response strategy. Public relations professionals are essential in spreading the information and keeping stakeholders happy (Ferguson et al., 2018). Much of the literature on social media involvement in crisis management has focused on stakeholder relationships (Meer et al., 2017; Hellsten et al., 2019; Plessis, 2018). However, Moller et al.'s (2018) study is one of the few studies that examined the impact of social media on building community resilience during and after the crisis. Thus, there has been very little integration between these two literature streams, social media crisis communication and public resilience (Williams et al., 2017). This study explored the literature on social media crisis communication and resilience and evaluated how social media activities such as crisis response and social media interaction can impact public resilience.

Hence, this study evaluates the social media crisis communication model for building public resilience with artificial neural network (ANN) analysis. Therefore, the study is presented as follows: Section $w$ discussed the literature review and research framework. Section 3 discussed the methodology via ANN. Section 4 covers the results, and section 5 discussion of the study. Finally, section 6 discussed the conclusion and future work.

\section{Literature Review}

The dominant theory in the crisis communication literature is situational crisis communication (SCCT) (Coombs, 2017; Bukar et al., 2020). The key strength of SCCT is the ability to examine response strategy to protect organizational reputation from negative public's response (Coombs \& Holladay, 2002). Liu et al (2011) social-mediated crisis communication (SMCC) is a social media-based crisis communication model that presents the various types of publics engage in crisis response, as active, inactives, and followers. Stewart and Wilson (2016) introduced the STREMII model for social media to address the 
dynamic nature of social media responses and crises. The STREMII model is a cyclic process model that depicts that crisis response on social media should be dynamic and interactive because of the nature of social media users. The unique feature of STREMII is the dynamic surveillance ability to improve public resilience.

The general structural path model was applied to investigate stakeholder's relationship, which depicts that the relationship changes in crisis times because of pressure, time of pressure, and uncertainty (Meer et al., 2017). Lambret and Baki (2017) introduced social media crisis management metrix and framework, which focused on providing an analytical framework for response strategies based on the stakeholder's emotions to crisis and attribution of responsibility. Whereas, Moller et al (2018) model, social-mediated disaster resilience (SMDR), is among the few that integrate social media crisis communication and resilience literature. The SMDR adopted the 3Rs resilience model (robust, rapid, and redundant) to demonstrate how social media can be used during and after the crisis to build resilience. Plessis (2018) adopted the dialogic communication theory to show how dialogue can increase stakeholders' relationships during and after crises. This suggests that the dialogic content should be open, responsive, transparent, and interactive. Similarly, the significance of interaction is also fueled by Cheng (2018) through the interactive crisis communication model (ICCM). The ICCM is the first model to provide a social media-based integrated strategy toolkit that synthesizes SCCT and crisis communications strategies into five primary crisis responses: dynamics for the social-mediated crisis. Hellsten et al (2019) used network theory to emphasize the three components of the issue: authors, topics, and addressed actors.

Recently, social media crisis communication for resilience (SMCCR) building further represents the nature of social media crisis response and interaction and integrates crisis management and communication with resilience (Bukar et al., 2020; 2021). The SMCCR builds upon the concept of SMDR, ICCM, and the dominant SCCT. The main strength of SMCCR is to demonstrate how social media usage, through social interaction and crisis response, can affect the ability of people to recover from the crisis. Furthermore, they show how social media interactions might benefit the community's resilience. Due to this being an attempt to stabilize a situation and enhance the connection, crisis management actions aim to bolster community resilience. To a great extent, crises prompt stakeholders to become more assertive and confident, showing how dedicated and proactive they will be in crises (Liu et al., 2011; Moller et al., 2018). The research framework, presented in Figure 1, shows the conceptualization of SMCCR and the relationship between crisis, social media interaction, crisis response, and resilience.

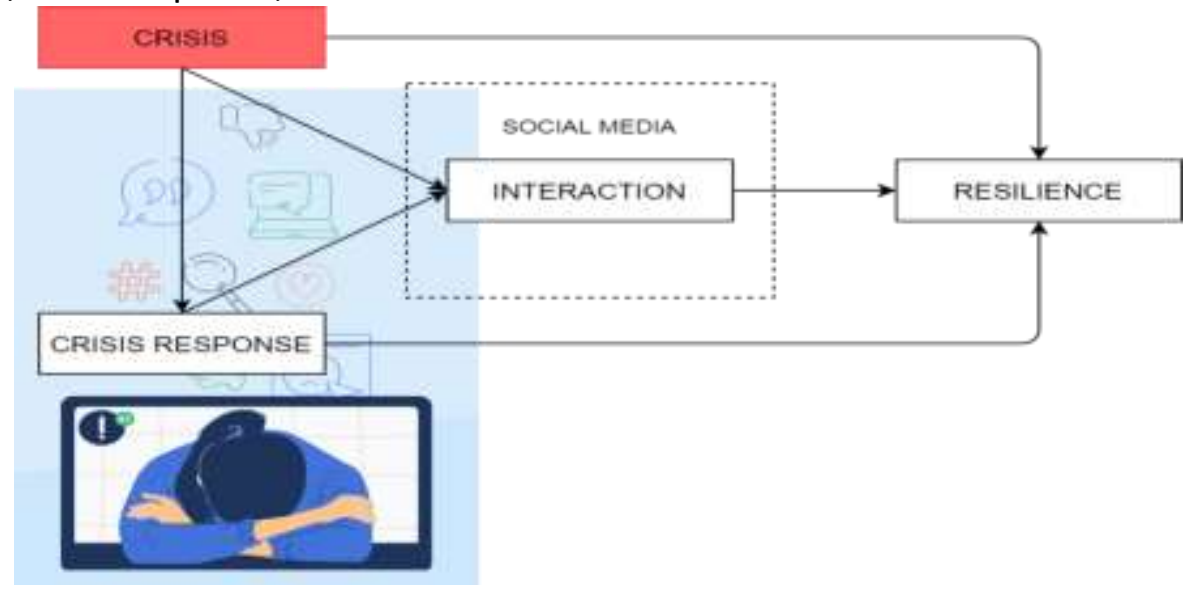

Figure 1: Research Framework 


\section{The Social Media Crisis Communication and Resilience Model}

A crisis is a feeling of fear, urgency, and impending disaster that impacts crisis response formation and leadership on social media. Crises can take a variety of forms, including natural disasters and human-caused crises. Some things related to crises are essential, including how long they occurred, how they began, and who are the victims, perpetrators, or catalysts (Liu et al., 2011; Cheong, 2011; Coombs \& Holladay, 2012; lannarino et al., 2015; DiStaso, 2015; Cheng, 2018; and Syed, 2018). The SMCCR model demonstrates that crisis has a notable impact on maintaining a high resilience community and social media use is an enabler through response and interaction.

According to SMCCR, crisis response is traditionally a formal communication rendered by the crisis management authority to calm the situation, render apology, provide warnings, or provide more information concerning the crisis. Social media has enabled the public as an actor in crisis communication (Liu et al., 2011). Both stakeholders are given the option to write and publish content about the crisis. According to the SMCC model, the public takes part in crisis response as "active" (those who directly address the problem), "passive" (those who observe and comment or share), and "inactive." The active user's also known as social media influencers, create or post content on social media. The passive users enjoy or share the information provided by influencers. The public's response can reveal the emotional states of the users. An adequate understanding of the public's response can help provide an effective crisis response approach (Liu et al., 2011; Stewart \& Wilson, 2016; Lambret \& Barki, 2018), which can significantly impact resilience building.

Moreover, the SMCCR reemphasizes why crisis communication should regard social media interaction as an avenue to facilitate effective crisis management and communication. Social media interactions occur between two or more persons or between people and organizations on social media. The social interactions enable information sharing, discussions, and warnings about the crisis. The possible effect of this interaction could be positive, Neural, or negative (Goggins et al., 2013; Valecha, 2019). This illustrates that social media activity has a substantial impact on the ability of people to recover from the devastating effect of the crisis.

Resilience is the ability to recover mentally or emotionally in the wake of a crisis or to return to pre-crisis conditions fast; the ability of the public to bounce back after a crisis. Understanding the public's capacity to endure a crisis is vital to determining the effects of crisis management (organization) efforts in the early stages of a crisis. During crisis management, the objective is to improve the relationship with the community and develop community resilience (Liu et al., 2011; and Moller et al., 2018). The SMCCR concluded that the factors presented in Figure 1.; crisis, crisis response, and social media interaction, substantially impact people's ability to recover from a crisis.

Consequently, the public has found that social media is powerful, allowing people to participate in crisis communication conversations, and has established social media as a crucial resource (Irons \& Paton, 2017). The information may be communicated more rapidly and extensively by using social media to address crises and connect with people. As a result, resisting the crisis is the first desirable outcome to follow, but making sure that the information is robust, speed, and redundancy is crucial for strengthening resilience in the face of a crisis or disaster (Moller et al., 2018). Because of this, it is vital to investigate to analyze the impact of social media usage. 


\section{Methodology}

In our effort to revisit the SMCCR, the study analyzed data using an artificial neural network (ANN). The neural networks were used to identify predictors and antecedents of resilience building (Scott \& Walczak, 2009). The previous study evaluated the SMCCR model using the PLS-SEM, which is commonly used to test the association between hypotheses and importance-performance map analysis (IPMA) (Chan \& Chong, 2012; Bukar et al., 2021). The PLS-SEM was used to create a linear model that frequently simplifies the complexities of managerial decisions (Venkatesh \& Goyal, 2010). Hence, this study recognized the non-linear interactions between predictors via the ANN method, which is rarely integrated into crisis communication literature (Li et al., 2019). The ANN aid in discovering complicated linear and non-linear relationships (Chan and Chong, 2012). Additionally, the ANN enables more exact anticipation than the standard regression technique (Joshi \& Yadav, 2018). Similarly, many researchers have combined ANN and PLS-SEM analysis in a variety of contexts. These include CRM adoption (Ahani et al., 2017), motivators of cloud computing (Sharma et al., 2016), wearable healthcare device and iOS adoption (Chong \& Bai, 2014), mobile social media use intention in emergencies (Li et al., 2019), and determinant of cloud computing (Qasem et al., 2020). As a result, this revisits the SMCCR model and ascertains the elements that significantly impact resilience via ANN analysis. The ANN technique was used to forecast resilience-building based on the significant factors identified by the previous study (Bukar et al., 2021).

\section{Research Data}

The dataset was adopted from previous studies about SMCCR (Bukar et al., 2021). The final responses comprise 393 observations from Malaysians aged 21 to 40 who have encountered Covid-19 shutdown and are adhering to the social distance rule to avoid crowded areas, selfisolate, or quarantine. The majority of respondents used social media to communicate virtually with friends and relatives during the Covid-19 movement control order (MCO) and received updates from crisis management and communication authorities.

\section{Results}

The analytical methodology used in this study is artificial neural networks (ANN). The ANN was used to rank the normalized relevance of each of the relevant predictors. This section goes into detail about the data analysis and findings.

\section{Neural Network Analysis}

Multiple regression analysis (MRA) and PLS-SEM are standard linear statistical techniques for determining the linear relationship between variables and simplifying complex decisionmaking processes (Liébana-Cabanillas et al., 2017). However, it is advised that an ANN is capable of easily recognizing non-linear relationships. The advantage of utilizing a neural network model is learning complex linear and non-linear correlations between predictors (Chan and Chong, 2012; Qasem et al., 2020). Additionally, the ANN is more adaptable and capable of higher prediction accuracy than the linear model(s). It may even outperform conventional statistical techniques, such as MRA (Ahani et al., 2017). However, ANN is ineffective at testing hypotheses and establishing causal relationships due to its "black-box" character (Liébana-Cabanillas et al., 2017). Thus, similar to existing studies (Sharma et al., 2016; Li et al., 2019; Qasem et al., 2020), this work applied ANN as the second stage analysis technique. Three layers comprise the application of the ANN method: "input layer," "hidden 
layer," and "output layer." The hidden nodes have no direct connection to the outside world (thus the name "hidden"). They are responsible for executing computations and transporting data between the input and output nodes (Jaafar et al., 2018). As illustrated in Figure 2, three independent variables examined in the previous study (Bukar et al., 2021) serve as the input for the ANN, while the dependent variable (resilience) serves as the output.

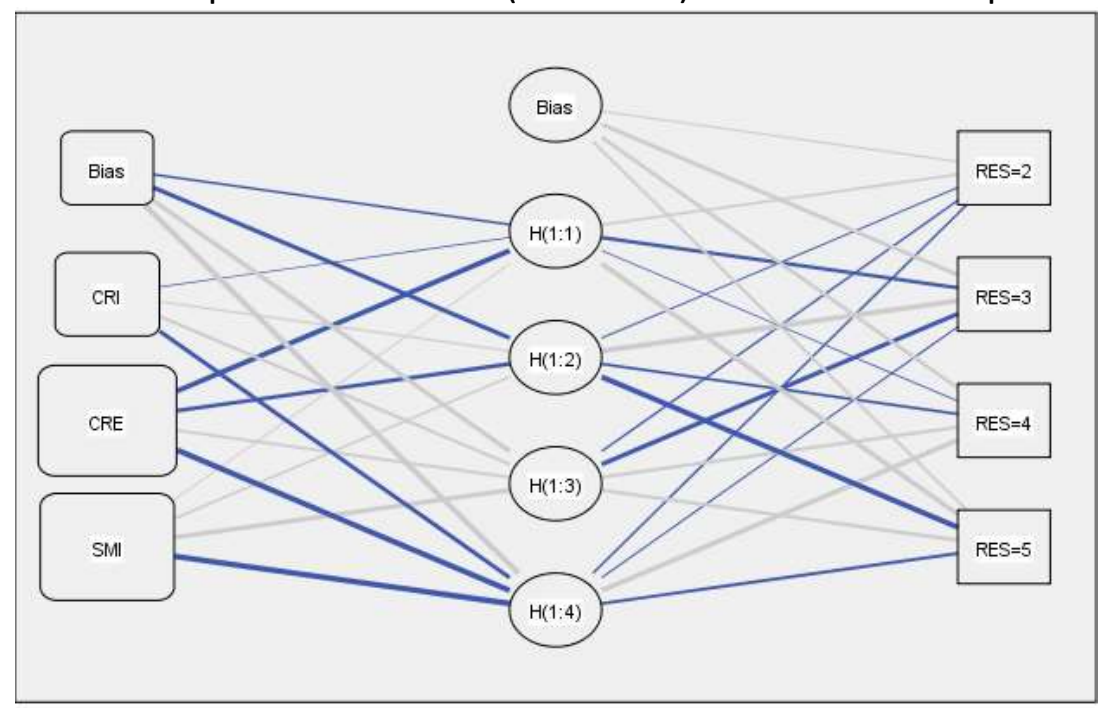

Figure 2: The Anticipated Neural Network Models.

Notes: Hidden and Output layer activation function: Hyperbolic tangent; Crisis (CRI); Crisis Response (CRE); Social Media Interaction (SMI); Resilience (RES).

The ANNs is calculated with a hidden node count ranging from 1 to 10 (Wang and Elhag, 2007), testing the ANN model by varying the number of hidden nodes from one to ten (Ahani et al (2017). This study applied the ten hidden nodes to determine the predictors' relative relevance. Following earlier work (Hew et al., 2018; Li et al., 2019), the analysis was conducted using the ANN module in SPSS 26. Specifically, we used a multi-layer perceptron with a back-propagation technique, as shown in Table 1 . Similarly, we created ten networks via tenfold cross-validation, using $70 \%$ of the data to develop the train network model, while $30 \%$ of the data validated the proposed model.

Three predictor variables were investigated: crisis, crisis response, and social media interaction. The output layer of the ANN model was used to calculate the factor "resilience," which is the dependent variable in this study. In both the training and testing datasets, sum of square error (SSE) and percent incorrect predictions (PIP) was utilized to determine the precision of the ANN model produced (Asadi et al., 2019). As indicated in Table 1, the average SSE for the training and testing methods is 66.1064 and 29.61, respectively, whereas the average PIP for training and testing is $33.75 \%$ and $35.11 \%$. The results demonstrate that the model fits reasonably. 
Table 1: SSE and PIP Values for ANN Model

\begin{tabular}{l|l|l|l|l}
\hline \multirow{2}{*}{ Network } & \multicolumn{4}{l}{ Training } \\
\cline { 2 - 5 } \multicolumn{1}{l}{ SSE } & \multicolumn{1}{l}{ Pesting } \\
\hline 1 & 62.678 & 34.1 & 30.909 & 33.6 \\
2 & 70.708 & 35.1 & 23.91 & 31.8 \\
3 & 62.641 & 33.6 & 36.59 & 35.2 \\
4 & 62.888 & 34.2 & 30.782 & 34.6 \\
5 & 64.217 & 33.3 & 32.446 & 35.8 \\
6 & 70.697 & 33.3 & 26.084 & 36.4 \\
7 & 68.295 & 34.6 & 27.613 & 33.1 \\
8 & 66.759 & 32.6 & 29.916 & 38.5 \\
9 & 62.552 & 31.3 & 32.911 & 41.5 \\
10 & 69.629 & 35.4 & 24.939 & 30.6 \\
Average & $\mathbf{6 6 . 1 0 6 4}$ & $\mathbf{3 3 . 7 5}$ & $\mathbf{2 9 . 6 1}$ & $\mathbf{3 5 . 1 1}$ \\
\hline
\end{tabular}

Input neuron: CRI, CRE, SMI; Output neuron: RES

Note: Crisis (CRI); Crisis Response (CRE); Social Media Interaction (SMI); Resilience (RES); Percent Incorrect Predictions (PIP).

Additionally, the model's significance is determined by the number of non-zero synaptic weights connected to relevant hidden parts (see Table 2). This demonstrates that the model has high predictive accuracy and that the model is reliable in depicting the relationship between predictors and output. Thus, the sensitivity analysis determines the predictors' relative relevance. The mean Importance of each variable was standardized. The ranks of the predictors were identical in terms of the normalized relevance of the ANN, as presented in Table 2 . Hence, the result shows that crisis response $(99.47 \%)$, social media interaction $(85.22 \%)$, and crisis $(67.06 \%)$ are significant predictors of resilience, in this order.

Table 2: Sensitivity Analysis based on Normalized Importance.

\begin{tabular}{lllllll}
\hline Network & \multicolumn{3}{l}{ Importance } & \multicolumn{3}{l}{ Normalized Importance (\%) } \\
\hline & CRI & CRE & SMI & CR1 & CRE & SMI \\
1 & .242 & .381 & .377 & 63.5 & 100 & 98.7 \\
2 & .211 & .384 & .405 & 52 & 94.7 & 100 \\
3 & .254 & .418 & .328 & 60.8 & 100 & 78.4 \\
4 & .318 & .344 & .338 & 92.3 & 100 & 98.3 \\
5 & .150 & .485 & .365 & 31 & 100 & 75.2 \\
6 & .330 & .407 & .262 & 81.1 & 100 & 64.3 \\
7 & .256 & .385 & .359 & 66.6 & 100 & 93.2 \\
8 & .308 & .405 & .287 & 76 & 100 & 70.9 \\
9 & .290 & .384 & .326 & 75.7 & 100 & 85 \\
10 & .275 & .385 & .340 & 71.6 & 100 & 88.2 \\
Average RI & .2634 & .3978 & .3387 & $\mathbf{6 7 . 0 6}$ & $\mathbf{9 9 . 4 7}$ & $\mathbf{8 5 . 2 2}$ \\
\hline
\end{tabular}

Note: Crisis (CRI); Crisis Response (CRE); Social Media Interaction (SMI); Resilience (RES); Relative Importance (RI). 


\section{Discussion}

This study intended to advance the crisis communication literature by presenting and evaluating an SMCCR framework that integrates the fundamental elements of prevalent social media-based crisis communication theories. This effort of evaluation allows us to identify prominent predictors of resilience. This approach enables us to make numerous valuable additions to the literature on crisis communication about social media and resilience.

The communication dynamics available in social media have evolved new power to social media users, including a sender-receiver relationship and a receiver-sender relationship in crisis life cycles. People are more concerned with the crisis management involved than just responding to the crisis. The public becomes more vocal when addressing other organizations involved and groups that are tied to political and social issues. The majority of social media crisis communication theories such as STREMII, ICCM, and SMDR demonstrated the impact of social interaction. They failed to consider the impact of these activities on resilience building. The present study is one of the earliest attempts to expose the effects of social interaction and crisis response on helping people recover. Our model can help better understand social media relationships, communicative behaviors, emotional reactions across the public, and resilience-building effects.

Furthermore, by evaluating resilience predictors and clarifying their purposes, this study contributes to the SMCCR model by providing a more detailed conceptualization and assessment of social media-based predictors during a crisis (Bukar et al., 2021). This also extends the motives of the SMDR model regarding the significance of social media effectiveness on resilience building. In addition, the explanations of social interaction in this study also extend the theory of Cheng (2018) by illustrating that the various influences of social interaction that engage the public as victims looking for social support or as citizens for providing social support to victims. Remarkbly, this study discovers many functions about the effect of technological solutions, particulalrly social media. More crisis management uses their social media profiles to interact with readers and page followers (AO \& Mak, 2021). It is worthwhile to study public and new media's roles, motivations, and actions in socialmediated crisis communication in the future. Conducting further studies are required to revisit the SMCCR model and improve the suggested model.

\section{Conclusion}

This study aimed to evaluate the social media crisis communication for resilience model via ANN methods. The ANN was used to assess the predictive influence of crisis, crisis response, and social media interaction on the ability of people to recover from the crisis. The data indicate that all the predictors, crisis response, social media interaction, and crisis- in this order, are significance. Mainly, the ANN model shows that crisis response and social media interaction are the most important predictors of resilience. This study has limitations, the most significant of which is that the test is based on a single analysis (ANN). Also, this study only reported SSE and does not consider root mean square error (RMSE) which is left for future research. Further research could be conducted to collect the content of crisis reactions from social media sites. Sentiment analysis can be used to determine the degree of engagement between stakeholders to predict resilience. 


\section{References}

Ahani, A., Rahim, N. Z. A., \& Nilashi, M. (2017). Forecasting social CRM adoption in SMEs: A combined SEM-neural network method. Computers in Human Behavior, 75, 560-578.

AO, S. H., \& Mak, A. K. (2021). Regenerative crisis, social media publics and Internet trolling: A cultural discourse approach. Public Relations Review, 47(4), 102072.

Asadi, S., Abdullah, R., \& Jusoh, Y. Y. (2019). An Integrated SEM-Neural Network for Predicting and Understanding the Determining Factor for Institutional Repositories Adoption. In Proceedings of SAI Intelligent Systems Conference (pp. 513-532). Springer, Cham.

Austin, L., Fisher Liu, B., \& Jin, Y. (2012). How audiences seek out crisis information: Exploring the social-mediated crisis communication model. Journal of applied communication research, 40(2), 188-207.

Bukar, U. A., Jabar, M. A., Sidi, F., Nor, R. N. H. B., Abdullah, S., \& Othman, M. (2020). Crisis Informatics in the Context of Social Media Crisis Communication: Theoretical Models, Taxonomy, and Open Issues. IEEE Access, 8, 185842-185869.

Bukar, U. A., Jabar, M., Sidi, F., Nor, R., Salfarina, \& Abdullah. (2021). The Influence of Crisis Response on Social Interaction and Public Resilience Based on ImportancePerformance Map Analysis (IPMA). Knowledge Management International Conference (KMICe) 2021, Volume 1, pp. 62-67.

Chan, F. T., \& Chong, A. Y. (2012). A SEM-neural network approach for understanding determinants of interorganizational system standard adoption and performances. Decision Support Systems, 54(1), 621-630.

Cheng, Y. (2018). How Social Media Is Changing Crisis Communication Strategies: Evidence from the Updated Literature. Journal of Contingencies and Crisis Management, Volume 26, pp. pp. 58-68.

Chong, A. Y. L., \& Bai, R. (2014). Predicting open IOS adoption in SMEs: An integrated SEMneural network approach. Expert Systems with Applications, 41(1), 221-229.

Coombs, W. T. (2017). Digital naturals and the rise of paracrises: The shape of modern crisis communication. New media and public relations, , 281-290.

Coombs, W. T., \& Holladay, J. S. (2012). The paracrisis: The challenges created by publicly managing crisis prevention. Public Relations Review, 38(3), 408-415.

Coombs, W. T., \& Holladay, S. J. (2002). Helping crisis managers protect reputational assets: Initial tests of the situational crisis communication theory. Management communication quarterly, 16(2), 165-186.

Ferguson, D. P., Wallace, J. D., \& Chandler, R. C. (2018). Hierarchical consistency of strategies in image repair theory: PR practitioners' perceptions of effective and preferred crisis communication strategies. Journal of Public Relations Research, 30(5-6), 251-272.

Goggins, S. P., Mascaro, C., \& Valetto, G. (2013). Group Informatics: A Methodological Approach and Ontology for Sociotechnical Group Research. Journal of the American Society for Information Science and Technology, 64(3), pp. pp. 516-539.

Groen, F. C., Pavlin, G., Winterboer, A., \& Evers, V. (2017). A hybrid approach to decision making and information fusion: combining humans and artificial agents. Robotics and autonomous systems, 90, 71-85.

Hellsten, I., Jacobs, S., \& Wonneberger, A. (2019). Active and passive stakeholders in issue arenas: A communication network approach to the bird flu debate on Twitter. Public Relations Review, Volume 45, pp. pages 35-48. 
Hew, J. J., Leong, L. Y., Tan, G. W. H., Lee, V. H., \& Ooi, K. B. (2018). Mobile social tourism shopping: A dual-stage analysis of a multi-mediation model. Tourism Management, 66, 121-139.

Irons, M. E. L. A. N. I. E., \& Paton, D. (2017). Social Media and Emergent Groups: The impact of high functionality on community resilience. Disaster Resilience: An Integrated Approach, 2nd ed.; Paton, D., Johnston, DM, Eds, 194-211.

Jaafar, K., Ismail, N., Tajjudin, M., Adnan, R., \& Rahiman, M. H. F. (2018). Artificial Neural Networks for Water Level Prediction Based on Z-Score Technique in Kelantan River. Int. J. Electr. Electron. Syst. Res, 13.

Joshi, R., \& Yadav, R. (2018). An integrated SEM neural network approach to study effectiveness of brand extension in Indian FMCG industry. Business Perspectives and Research, 6(2), 113-128.

Lambret, C. V., \& Barki, E. (2018). Social media crisis management: Aligning corporate response strategies with stakeholders' emotions online. J Contingencies and Crisis Management, Volume 26, pp. pp. 295-305.

Li, Y., Yang, S., Zhang, S., \& Zhang, W. (2019). Mobile social media use intention in emergencies among Gen $Y$ in China: An integrative framework of gratifications, tasktechnology fit, and media dependency. Telematics and Informatics, 42, 101244.

Liébana-Cabanillas, F., Marinković, V., \& Kalinić, Z. (2017). A SEM-neural network approach for predicting antecedents of m-commerce acceptance. International Journal of Information Management, 37(2), 14-24.

Liu, B. F., Austin, L., \& Jin, Y. (2011). How publics respond to crisis communication strategies: The interplay of information form and source. Public Relations Review, Volume 37, pp. pp. 345-353.

Meer, T. G. V. D., Verhoeven, P., Beentjes, H. W., \& Vliegenthart, R. (2017). Communication in times of crisis: The stakeholder relationship under pressure. Public Relations Review, Volume 43, pp. pages 426-440.

Mmonu, N. A., Aifah, A., Onakomaiya, D., \& Ogedegbe, G. (2021). Why the global health community should support the EndSARS movement in Nigeria. The Lancet, 397(10275), 666-667.

Moller, C., Wang, J., \& Nguyen, H. T. (2018). \#Strongerthanwinston: Tourism crisis communication through Facebook following tropical cyclones in Fiji. Tourism Management, Volume 69, pp. pages 272-284.

Morgan, A., \& Wilk, V. (2021). Social media users' crisis response: A lexical exploration of social media content in an international sport crisis. Public Relations Review, 47(4), 102057.

Noguti, V. (2016). Post language and user engagement in online content communities. European Journal of Marketing.

Plessis, C. d., 2018. Social media crisis communication: Enhancing a discourse of renewal through dialogic content. Public Relations Review, Volume 44, pp. pp. 829-838.

Qasem, Y. A., Asadi, S., Abdullah, R., Yah, Y., Atan, R., Al-Sharafi, M. A., \& Yassin, A. A. (2020). A Multi-Analytical Approach to predict the determinants of cloud computing adoption in higher education institutions. Applied Sciences, 10(14), 4905.

Rahman, K. A. (2020). News media and the Muslim identity after the Christchurch mosque massacres. Kōtuitui: New Zealand Journal of Social Sciences Online, 15(2), 360-384. 
Reuter, C., \&Kaufhold, M.-A. (2018a). Fifteen years of social media in emergencies: A retrospective review and future directions for crisis Informatics. J Contingencies and Crisis Management., Volume vol. 26, p. pp. 41-57.

Reuter, C., Ludwig, T., Kaufhold, M. A., \& Spielhofer, T. (2016). Emergency services' attitudes towards social media: A quantitative and qualitative survey across Europe. International Journal of Human-Computer Studies, 95, 96-111.

Reuter, C., Hughes, A. L., \& Kaufhold, M. A. (2018). Social media in crisis management: An evaluation and analysis of crisis informatics research. International Journal of HumanComputer Interaction, 34(4), 280-294.

Schleicher, A. (2020). The impact of covid-19 on education insights from education at a glance 2020. Retrieved from oecd. org website: https://www. oecd. org/education/theimpact-of-covid-19-on-education-insights-education-at-a-glance-2020. pdf.

Scott, J. E., \& Walczak, S. (2009). Cognitive engagement with a multimedia ERP training tool: Assessing computer self-efficacy and technology acceptance. Information \& Management, 46(4), 221-232.

Sharma, S. K., Al-Badi, A. H., Govindaluri, S. M., \& Al-Kharusi, M. H. (2016). Predicting motivators of cloud computing adoption: A developing country perspective. Computers in Human Behavior, 62, 61-69.

Stewart, M. C., \& Wilson, B. G. (2016). The dynamic role of social media during Hurricane \#Sandy: An introduction of the STREMII model to weather the storm of the crisis lifecycle. Computers in Human Behavior, pp. pp. 639-646.

Venkatesh, V., \& Goyal, S. (2010). Expectation disconfirmation and technology adoption: polynomial modeling and response surface analysis. MIS quarterly, 281-303.

Wang, Y. M., \& Elhag, T. M. (2007). A comparison of neural network, evidential reasoning and multiple regression analysis in modelling bridge risks. Expert Systems with Applications, 32(2), 336-348.

Williams, T. A., Gruber, D. A., Sutcliffe, K. M., Shepherd, D. A., \& Zhao, E. Y. (2017). Organizational response to adversity: Fusing crisis management and resilience research streams. Academy of Management Annals, 11(2), 733-769.

Zheng, B., Liu, H., \& Davison, R. M. (2018). Exploring the relationship between corporate reputation and the public's crisis communication on social media. Public Relations Review, 44(1), 56-64. 